\title{
QUANTUM PHYSICS IN TEACHER EDUCATION
}

\author{
Gesche Pospiech, Matthias Schöne, TU Dresden, Faculty of Science
}

\begin{abstract}
Teacher education forms the decisive link between physics education research and the realization of research results in school. The actions of teachers are influenced by their own experience from school, from study at university and the need to follow the school curriculum. Discrepancies between these factors have to be overcome. In quantum physics, the gap between teaching traditions at university, recent experimental results and the possibilities of teaching at school is especially big. Therefore it seems desirable to study this gap in detail in order to diminish it within given resources.
\end{abstract}

\section{Introduction}

Quantum physics is the basic theory of physics. During the last decades there has been made significant progress in understanding its fundamental features as opposed to classical physics. Especially experiments concerning uncertainty, entanglement and quantum information allow for deeper insight and have found their way into popular science (e.g. Zeilinger 2003). In this way the fascination of youth towards quantum physics is raised.

However, in general these new developments do not yet find their way into the school curricula and also not into teacher education. On the contrary the teaching at school is strongly influenced by the historical developments, such as the atomic model, the representation of e.g. an electron by the so-called wave-function or the statistical interpretation of the uncertainty relation of position and momentum as central parts. Whereas it is undoubted that quantum physics as a basic theory has to be taught at school it is not equally clear which aspects to choose as the most relevant content. Therefore the implementation of a modern course in quantum physics be at school or at university requires big efforts in several aspects: first it needs the definition of an agreed upon "canon" for school and university alike and secondly identifying appropriate learning pathways.

The decision of teachers regarding the focus of their lessons relies on several factors: their own experience as students in school, their own convictions about good physics teaching and its related goals, what they have learned at university and last but not least the school curriculum with the expected teaching. In addition, teaching quantum physics is strongly connected with the personal views on the role of physics and its statements it can make as a science and where its borders are.

Teacher education has to cover mastering the basics of quantum physics - including some mathematical formalism - and on the other hand being able to explain it to students. In university lectures on quantum physics these both combined goals mostly are not reached in such a way that the teachers transfer their knowledge into the classroom. So the adequate fitting of content knowledge and pedagogical content knowledge remains an open problem. The goal of the present study is to go a first step towards its solution in describing the relation between the conceptions of the lecturers at university and the students' conception of the relevant quantum physics terms and the interrelations.

\section{Theoretical Framework}

Teacher education lies in the triangle between the professional knowledge teachers are expected to acquire at university, their own experiences from the physics lessons they attended themselves at school and the demands of school curricula, lesson plans and school authorities, (Etkina 2010). In order to devise their teaching teachers have to combine their content knowledge, the pedagogical knowledge and the pedagogical content knowledge. This is seen through the glasses of personal convictions, teaching habitudes and cornered by the school curriculum.

\subsection{Teaching of Quantum Physics}

Quantum physics proves to be a special area in physics teaching because of its abstract formalism, the differences to classical physics, the nearly complete absence of real experiments suitable for school and the strong traditions in teaching partly due to the long unclear history of 
interpretation. In addition, in quantum physics as a vivid research area with numerous experiments concerning its fundamentals, there is an exceptional discrepancy between concepts revealed by recent research and the more traditional views of teaching at school. Many courses at school (and at university) start with the photoeffect in order to introduce light as particle and in the sequence guiding the students towards quantum objects and the double slit experiment. During this learning path students tend to retain classical notions; they might still think: "finally, the electron must take some path or other" (Fanaro et al 2009)

In modern presentations of quantum physics the terms of superposition, uncertainty and entanglement play a central role, (Michelini 2000, Pospiech 1999). Michelini and her group have developed a didactical path along the core concepts of quantum theory: the superposition principle and uncertainty, strongly related to phenomenology treating the polarization of photons interacting with polarizers and birefringent crystals, in the end leading to the formalism. For the use of teachers a web site has been constructed (Santi et al, 2011). But this approach is not typical for university lectures on quantum physics.

In each learning pathways learning difficulties of students can be observed. A broad range of studies on high school students and university students analyzes conceptions of quantum mechanics (for a short overview see (Akarsu, 2011)). Students' difficulties in understanding and acquiring an adequate quantum view depend not only on the subject in question - atomic model, uncertainty relation or wave function - but also on preliminary instruction, (Baily\&Finkelstein 2009). Many students do not exhibit a consistent perspective on uncertainty and measurement across multiple contexts. A more refined study (Baily\&Finkelstein, 2010) focuses on the change of students perspective depending on the views of the instructor as well as on own personal convictions about the "real world", (see also Levrini et al 2008). Baily and Finkelstein find that the students' views on quantum mechanical phenomena can be significantly changed by instruction, e.g. by explicitly teaching the quantum perspective, but may stay mixed between classical and quantum interpretation.

However, there are nearly no studies taking teacher students into the view. One exception is a study concerning the conception of atomic model (Kalkanis, 2002). The problems of teacher students mostly are the conceptual understanding and the interpretation of quantum physics. Often students calculate without a mental concept (Robertson/Kohnle 2010), the indeterminism and the measuring process are not understood and the classical views, like trajectories or fixed properties remain unchanged (Müller/Wiesner 1998). Mannila et al (2001) found differences between students preparing for teacher and future physicists with teacher students tending more to a quantum view. Because of the small number of participants it is not clear whether this is a general feature.

Concerning teachers researchers find that they have limited viewpoints about quantum mechanics. The teachers relate between quantum mechanic concepts and classical ideas in an undifferentiated way. This is a big obstacle in the teaching process in school in the light of a recent study showing that - quite independent from the teaching approach - especially concepts taught in quantum physics are very stably retained, (DesLauriers \& Wieman 2011). This hints to the importance of the above mentioned triangle of previous experiences of teacher students for their future learning and directs the focus onto teacher education.

\subsection{Teacher professionalisation}

Studies show that the quality of teachers' explanations strongly depends on their content knowledge, (Baumert et al. 2010, Riese 2010). It has to be flexible and adjusted to their students needs. An effective teacher is the single most important factor of student learning (DarlingHammond, 2000).

Demtröder et al (2006) argue that teaching physics is an own profession, not a part of the education for future physicists and has to be a study course of its own. Besides theoretical instruction Pedagogical Content Knowledge (PCK), like methodical didactical knowledge, discussion of historical and philosophical question, interpretation of quantum physics concepts and main modern applications, is necessary to teach quantum physics well in school. 
So adequate teacher formation at university has to be developed, especially as it turns out that the most relevant learning period concerning content knowledge seems closed after the "Referendariat" (Borowski, 2011). In an approach to teacher preparation (Kalkanis, 2002) five interactive components of an instructional model are identified: exploring learners pre-instructional knowledge, the content analysis from the educational perspective, identifying the learners needs, fostering the reconstructing of knowledge and meta-cognitive activities. Because in quantum physics the concepts are retained exceptionally well (Deslaurier\&Wieman 2011) this procedure is of great importance. A study from Bagno et al (2010) showed that teachers need extensive qualitative discussions besides a founding in the formal aspects of quantum theory. But in many courses teachers learn quantum physics with a strong focus on mathematical formalism. As a consequence teacher students often do not know the didactical possibilities to teach quantum physics.

To explain the context of the study teacher education in Germany will be explained in a few remarks. Teachers study two subjects, e.g. physics and mathematics, with equal weight. Part of the study are lectures and seminars on general pedagogy. During their physics study they learn experimental physics, theoretical physics and attend laboratory work. In addition there are special seminars and lectures on pedagogical content knowledge. The physics course covers all the basic areas of physics. Generally only few of these lectures are specially prepared for teacher students but mostly are designed for students choosing physics as their major. However, in Saxony the lectures in theoretical physics are given separately for teacher students. With respect to quantum physics this opens up special possibilities for analyzing the gap between university and school curriculum.

\section{Design of Study}

In this study we concentrate on the relation between the actual teaching and learning of quantum physics at university in the special case of teacher education. On the basis of these results an additional course with emphasis on PCK in quantum physics will be developed. As a first step the status quo is being described.

\subsection{Research Questions}

First we analyze the fit between lecturer views and the view and demands of teacher students concerning lectures in quantum physics. The questions are:

A Which are the central concepts taught by lecturers?

A How do students grasp and understand these concepts?

A Which of these concepts are suited for teaching at school according to the view of teacher students?

\subsection{Methodology}

The goals and main content of the quantum physics course given by the lecturers were collected by a written questionnaire with open-ended questions. They were also asked about the obstacles in teaching, relevant topics and concepts, they wanted to teach to students, a rating of students pre-knowledge and if they make any differences between teacher students and future physicists.

For the teacher students' views a pilot interview study was started with five students to find the content of theoretical lectures, demands for an additional course and suitable topics for teaching quantum physics at school. Also a test of understanding was made with a german translation of tests of Robertson/Kohnle (2010) and Baily/Finkelstein (2009) as an anchoring test with respect to the learning difficulties described in the studies above. The topics of this test were quantum mechanical measurement, probabilities, possibilities oft interpretation, entanglement and EPR (Einstein, Podolsky, Rosen) Experiment, non determinism and uncertainty principle. In addition the interviewed student should rate the sufficiency of the content and the pedagogical content knowledge and their own understanding after their standard course in quantum physics.

The answers were of both groups to open questions or interviews were analyzed with the qualitative content analysis after Mayring (2010) to find the main categories. To compare the 
interview results concept maps of the categories were built with the program Atlas.ti@. The main categories were defined as best linked with other categories or often mentioned in the interviews. Based on this analysis we created a main quantitative questionnaire containing questions on the main contents of the lectures, the demanded content for an additional didactical course and suitable topics for a school course in quantum physics, a rating of imparted PCK and CK knowledge after a standard course and a self rating of the quantum physical understanding.

\section{Results}

\subsection{Results of analysis of lectures}

The main concepts of the standard courses in quantum physics from lecturers' point of view are shown in Fig. 1 as a concept map.

Lecturers put a great focus on mathematical techniques. One possible reason may be that lecturers often rate students' mathematical knowledge as insufficient and that it has to be enlarged. So the ability for doing formal calculations and mathematical analysis of quantum physics are two of the main goals of the lecturers. Other important goals are the knowledge of basic concepts and example applications. But no lecturer mentioned methodical or didactical concepts as important. Lecturers often feel there is too few time for these additional questions and/or they are not trained in this respect.

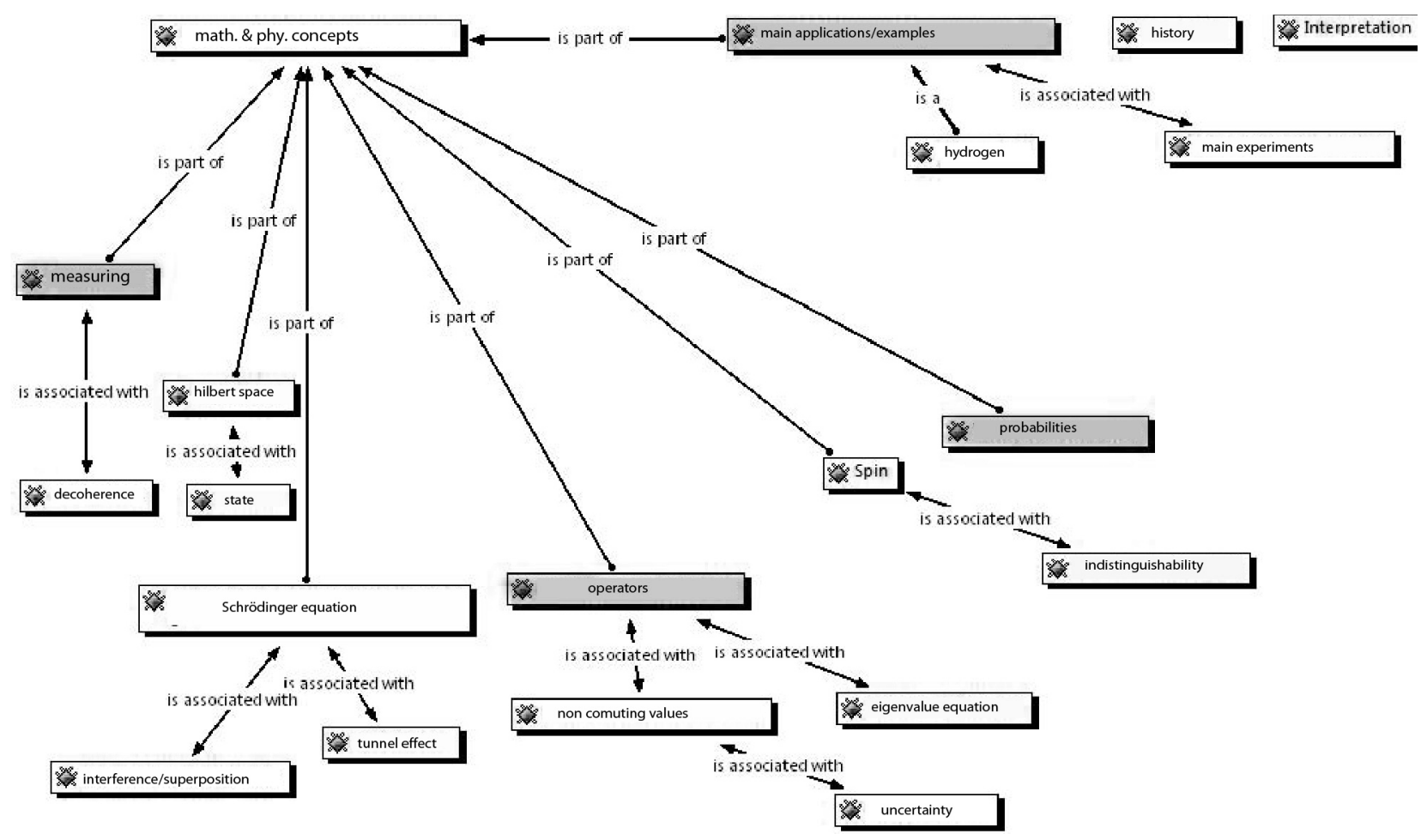

Figure 1: Main concepts according to lecturers. The most important topics are marked grey.

\subsection{Results of pilot study with teacher students}

As a first result of the pilot study the five different interviews with the students were analyzed and different categories for the content of theoretical physics courses, the demands for an additional 
didactical course and possible topics for teaching quantum physics in school were created. The main content of the lectures from the students point of view are shown in Fig.2 as a concept map.

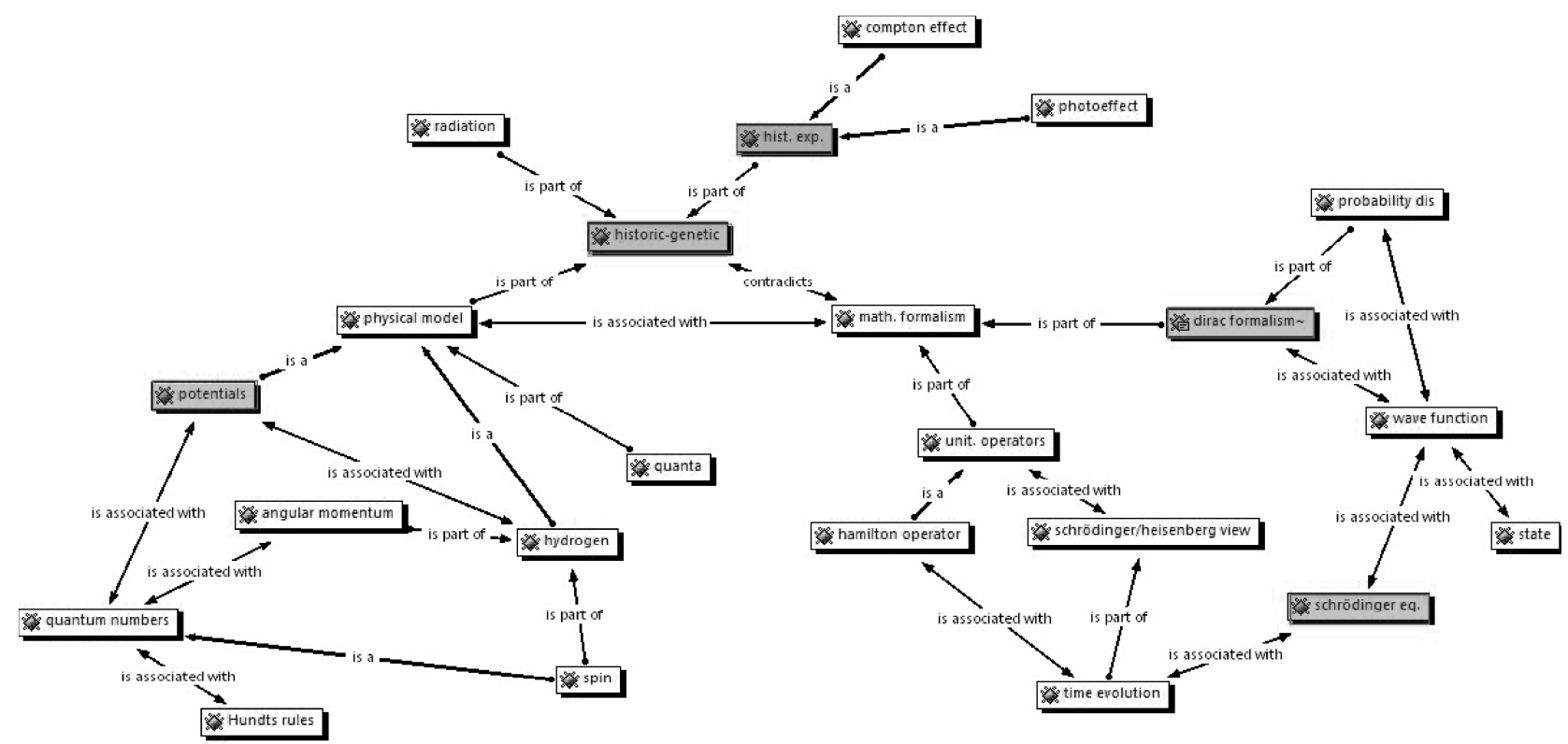

Figure 2: Main contents of lectures - seen by students. The most important topics are marked grey.

The identified categories were used as different choices in the quantitative main questionnaire, so a rank order of these topics could be constructed. In contrast to the lecturers' view students see more details like the Compton or photo effect than main principles. They separate more between physical model and mathematical formalism. Also students connect general quantities to concrete examples, e.g. Spin is related to hydrogen atom, but indistinguishability not at all. Also the main demands of the students for an additional course that improves the didactical education were categorized and are shown in Fig. 3, the main demands also marked grey.

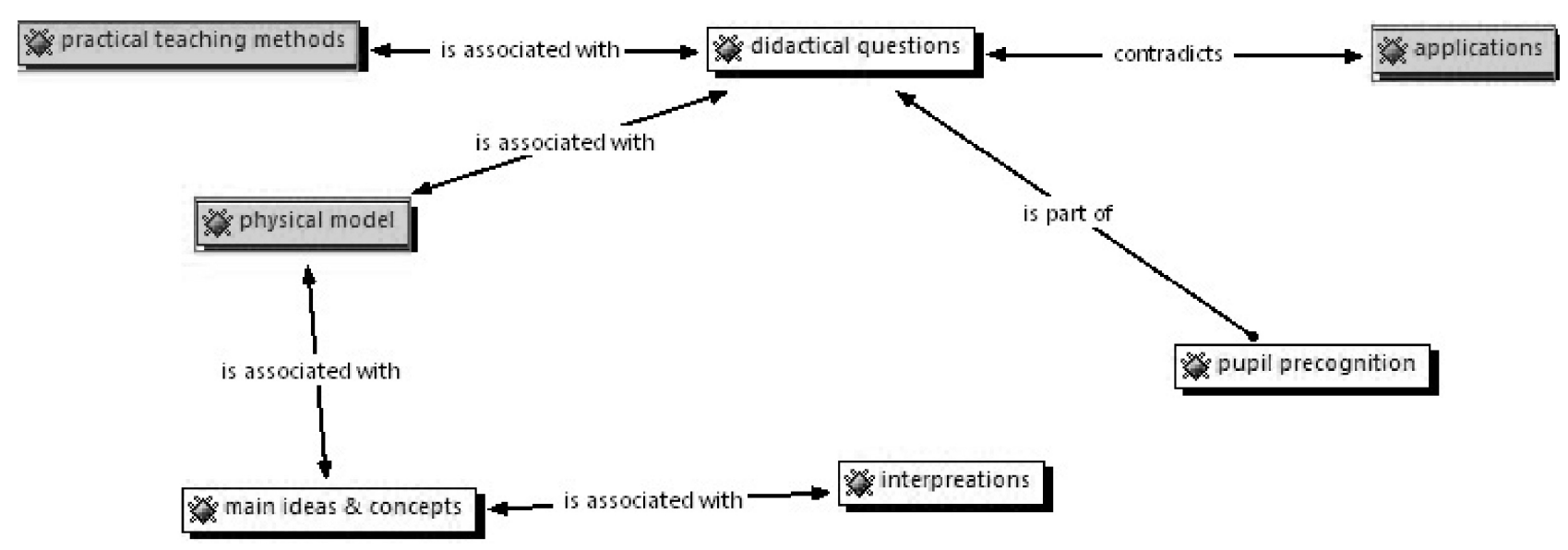

Figure 3: Students demands for an additional didactical course

As a second part the answers in the test for understanding were analyzed. Three of five students formally knew the problems of the measuring process in quantum physics, but none respectively 
only one could apply this knowledge to two questions about energy measurement (see Robertson/Kohnle 2010, question 1.1 and 1.2). In contradiction $90 \%$ of the comparable experimental group of Robertson/Kohnle could give the right answer to question no. 1.1 and 35\% to question no. 1.2 .

Concerning the explanation of quantum properties the uncertainty could be described by four of five students, but none could describe the difference between the uncertainty in a classical Galton Board experiment (for further details see Baily/Finkelstein 2009, essay question no. 2) and quantum uncertainty. This is almost in agreement to the result of Baily/Finkelstein with $15 \%$ right answers.

Only two of five students in our survey could describe the indeterminism and the entanglement correctly. None of the students knew the significance of the EPR Experiment.

\subsection{Results of Questionnaire}

In the main study 20 master students participated, mainly from the fifth year at universities in Dresden and Leipzig.

The content view of the master students in the quantitative survey is similar to the qualitative one. Main subjects like the Dirac formalism, the Schrödinger equation and calculus of potential wells are mentioned often, but historical experiments seem not so important for this group. In addition they put more attention to angular momentum/spin and mathematical formalism, e.g. the description of the time evaluation, so they are closer to the lecturers view.

The main demands of the students are also a stronger explanation of the physical model in interpretation questions but mainly PCK questions in practical teaching methods (18 of 20 students), concepts for a teaching unit (17 of 20 students), application examples (14 of 20 students) and general educational viewpoints (16 of 20 students). This is in accordance to the rating of students own learned PCK in quantum physics lectures. $70 \%$ of the students think the given knowledge is not sufficient for teaching quantum physics well in school. In contradiction students feel well prepared in their content knowledge. 16 of the 20 interviewed students think the main concepts of quantum physics became clear. But not all subdomains were equally rated, only 11 of 20 of the students feel well prepared in the topic of entanglement, 12 of 20 in uncertainty and only 8 of 20 in the understanding of the measurement process. In accordance to the lecturers' view only 12 of 20 students feel sufficiently prepared in the mathematical formalism.

The analysis of suitable topics for school courses in quantum physics show that the uncertainty principle, application of laser and properties of quantum objects are recommended by all students. Also the photo effect (19 of 20 students) and interference experiments (17 of 20) were seen as suitable topics.

Many topics from the university lectures like angular momentum, Schrödinger equation, Bose Einstein Condensation, probability distribution and equations of radiation, which are difficult, were rejected by the students for school education.

Visionary application topics like quantum computer or cryptography are rated ambiguous. This shows that students often reconstruct their own school experience, especially in historical experiments, but are open for new subjects like applications if they are well constructed. The analysis of the central points of the saxonian school curriculum (2011) shows similar topics with photon as a quantum object, the photo effect, interference of photon, electron and neutron and Heisenberg's uncertainty principle. Only the measurement process was not mentioned by the students, but is a main topic in the curriculum. It is remarkable that lecturers are focused on mathematical formalism, which cannot be used in school, because only basics of vector algebra are known by the pupils.

\section{Future work}

In order to compare content structures of university and school lectures it is planned to analyze two different concept maps. One is built up from lecture scripts and exercises of university lectures, the 
other from school books. Hendrik Härtig has shown in his dissertation (2010), that school books are with high significance a good indicator for the average school lesson. To validate both concept maps experts will analyze and verify them.

To improve the pedagogical content education of teacher students we are planning an additional course. Main goals of this course is the discussion of basic ideas of quantum physics, fundamental experiments and possible problems in the teaching learning process. But also teaching concepts in quantum physics and practical developments by students will be included.

The course will be evaluated with a pre- and posttest with qualitative instruments and a questionnaire.

\section{Conclusion}

This study shows that lecturers and teacher students have different views and demands for a reasonable course in quantum physics. Lecturers see basic mathematical techniques and quantum physics formalism as main goals. Teacher students want to understand the basic principles, interpretational problems and like to discuss PCK relevant questions, like practical teaching methods, teaching concepts and applications.

It was shown that teache students feel well prepared in the content knowledge but poorly in pedagogical content knowledge with the consequence that they fell not prepared to teach quantum physics in school. We will analyze the effects of an additional course especially for teacher students in this respect.

\section{References}

Akarsu B (2011) Instructional Designs in Quantum Physics: a Critical Review of Research, Asian Journal of Applied Sciences 4(2), 112-118

Fanaro M, Otero M R \& Arlego M (2009) Teaching the foundations of quantum Mechanics in Secondary School: a Proposed Conceptual Structure, Investigações em Ensino de Ciências 14(1), 37-64

Eylon B, Cohen E, Bagno E (2010) The interplay of physics and mathematics in a graduate quantum mechanics course for physics teachers, talk given in GIREP-conference 2010 in the Symposium "Addressing the role of mathematics in physics education.

Baily C \& Finkelstein N (2009) Development of quantum perspectives in modern physics, Physical Review Special Topics - Physics Education Research 5, 010106

Baily C \& Finkelstein N (2010) Refined characterization of student perspectives on quantum physics, Physical Review Special Topics - Physics Education Research 6, 020113

Baumert J, Kunter M, Blum W, Brunner M, Voss T, Jordan A et al. (2010) Teachers' mathematical knowledge, cognitive activation in the classroom, and student progress, American Educational Research Journal, 47(1), 133-180

Borowski A, Kirschner S, Liedtke S \& Fischer H E (2011) Vergleich des Fachwissens von Studierenden, Referendaren und Lehrenden in der Physik, Physik und Didaktik in Schule und Hochschule 10(1), 1-9

Deslaurier L \& Wieman C (2011). Learning and retention of quantum concepts with di erent teaching methods. Physical Review Special Topics - Physics Education Research, 7, 010101

Darling-Hammond L (2000) Teacher Quality and Student Achievement: A Review of State Policy Evidence, Education Policy Analysis Archives 8(1), 1-44

Demtröder et al (2006) Thesen für ein modernes Lehramtsstudium im Fach Physik, DPG

Etkina E (2010) Pedagogical content knowledge and preparation of high school physics teachers, Physical Review Special Topics Physics Education Research 6, 020110

Kalkanis G, Hadzidaki P \& Stavrou D (2003) An Instructional Model for a Radical Conceptual Change Towards Quantum Mechanics Concepts, Science \& Education 87, 257-280

Levrini O, Fantini P, Pecori B (2008) "The problem is not understanding the theory, but accepting it": a study on students' difficulties in coping with Quantum Physics, in GIREP-EPEC Conference, Frontiers of Physics Education Selected contributions, RIJEKA Zlatni rez, 319-324

Mannila K, Koponen I T \& Niskanen J A (2002) Building a picture of students' conceptions of wave- and particle-like properties of quantum entities, European Journal of Physics 23, 45-53

Mayring P (2010) Qualitative Inhaltsanalyse: Grundlagen und Techniken, Beltz

Michelini M, Ragazzon R, Santi L \& Stefanel A (2000) Proposal for quantum physics in secondary school, Physics Education 35(6), 406-410 
Müller R, Wiesner H, (1998) Vorstellungen von Lehramtsstudenten zur Interpretation der Quantenmechanik H. Behrendt (Hrsg): Zur Didaktik der Physik und Chemie, Alsbach, S. 382.

Pospiech G (1999) Teaching the EPR--Paradox at High School?, Physics Education 34, 311-316

Riese J (2010) Empirische Erkenntnisse zur Wirksamkeit der universitären Lehrerbildung - Indizien für notwendige Veränderungen der fachlichen Ausbildung von Physiklehrkräften, Physik und Didaktik in Schule und Hochschule, 9, 25-33

Robertson E, Kohnle A (2010) Testing the Development of Student Conceptual Understanding of Quantum Mechanics, GIREPEPEC PHEC 2009 Conference (2010), 261-273

Santi L, Michelini M, Stefanel A \& Meneghin G (2011) A resource environment for preservice teacher education to introduce quantum physics in secondary school , in 'MPTL conferrence 2010' 